\title{
Diaper Dermatitis in Elderly
}

\author{
Bonifaz $A^{*}$, Saldaña M, Escandón-Pérez $S$ and Tirado-Sánchez $A$
}

Mycology Department, Hospital General de Mexico, Mexico City, Mexico

“Corresponding author: Bonifaz A, Mycology Department, Hospital General de Mexico, Mexico City, Mexico, Tel: +52 55 57613923; E-mail: a_bonifaz@yahoo.com.mx Received date: July 23, 2017; Accepted date: September 19, 2017; Published date: December 28, 2017

Copyright: ( 2017 Bonifaz A, et al. This is an open-access article distributed under the terms of the Creative Commons Attribution License, which permits unrestricted use, distribution, and reproduction in any medium, provided the original author and source are credited.

\begin{abstract}
Diaper area dermatitis in elderly is usually associated with urinary incontinence, or mental disorders such as Alzheimer's, is an acute and irritant dermatitis caused by disposable diapers. Clinically presents with erythema, edema, erythematous-squamous plaques, papules and satellite lesions. Its association with Candida spp. is over $60 \%$, been the most important Candida albicans and Candida glabrata. The control of the disease is done with constant exchange of diapers, and use of emollients, in cases associated with Candida spp. the use of topical and systemic antimycotics is necessary.
\end{abstract}

Keywords: Diaper dermatitis; Elderly; Urinary incontinence; Candida albicans; Candida non-albicans

\section{Background}

Diaper dermatitis (DD) is an acute irritant and inflammatory dermatitis of the perineal and perianal area, is a very frequent entity in children $[1,2]$. However, it can also occur in adults and the elderly due to the use of disposable diapers in patients with urinary incontinence or bedridden in hospitals, especially in the ICU or with several mental disorders especially Alzheimer's disease, their constant use is the great solution for the management and retention of urine and feces $[3,4]$. Unlike the studies in children, Diaper Dermatitis in Elderly (DDE) data is not known precisely because there are few studies reported, therefore there are no data on prevalence or incidence $[3,4]$. Our main objective is to make a short review and commentary on diaper dermatitis in the elderly and provide some therapeutic options for its management and control.

\section{Pathogenesis}

It is considered that, like children, the diaper in the elderly causes skin irritation and most cases resolve in one or two days without treatment, however cases that exceed three days usually complicate, particularly because they are associated with Infections [1-3]. It is important to note that most cases are related to urinary incontinence because urine alone is a primary irritant to the skin $[5,6]$. However, the pathogenesis of DDE is not known, but it can be compared with what is known in children, that their development is complex and multifactorial, factors that may interfere are: increase of $\mathrm{pH}$ (by microbial flora); excessive humidity, which generates more friction with direct damage to the skin barrier; production of ammonium hydroxide (by increasing $\mathrm{pH}$ ); presence of lipases and proteases (by contact with feces), these are irritating to the skin generating severe erythema and cutaneous damage, humidity and several proteolytic enzymes have been found to degrade filaggrin, which has been described as a natural moisturization factor (NMF), and higher level of transepidermal water loss (TEWL), both factors act on the direct function of the cutaneous barrier $[7,8]$ the association of microbial flora is very important, of the most reported bacteria is Staphylococcus aureus, some even methicillin resistance strains; in a lower proportion: Streptococcus spp. ( $\beta$-hemolytic) and Escherichia coli [4,9]. However, the most important infectious association as well as children is with Candida yeasts, particularly Candida albicans, which has been reported in more than $60 \%$ [10]. However this number may be higher depending on the duration of the diaper and especially the presence of feces, in our experience is $80 \%$. Yeasts act as an opportunistic secondary infection, but its treatment is necessary, most come from the intestinal flora, vaginal and oral.

In the case of $\mathrm{DD}$ of the infant is mostly caused by $C$. albicans, yeasts that are sensitive to most treatments; however in the adult and elderly the presence of the group Candida no-albicans is larger, and it must be emphasized that species such as Candida glabrata has a greater presence (in the vagina and mouth), and therefore can be an irritated skin colonizer of the diaper area, the importance of this is that they are species that get easily acquired resistance to treatments such as fluconazole and other antimycotic agents $[4,11]$. In a study that we conducted (Table 1), predisposing factors and etiology were observed; the latter group reported that the non-albicans group was approximately $31.6 \%$. The presence of Candida spp. in the diaper area is stimulated because they are acidophilic, and when the $\mathrm{pH}$ increases, they are easily adapted by pair genes, PHR2 (acid) and PHR1 (neutral or basic) [12].

As in children the DDE can be controlled with constant changing of diapers, so with the use of high-tech diapers like: hypoallergenic, superabsorbent (sodium polyacrylate) $[1,2,4]$ and specially the breathable diaper [9], which have micropores that allow evaporation, and compared to traditional diapers reduce half of $\mathrm{DD}$, there is even a study in adults (healthy volunteers) comparing both diapers, in which C. albicans was inoculated, and it was observed that breathable diapers reduced by $62 \% \mathrm{CFU}$ (Colony Forming Unit) [9]. The disadvantage is the cost that does not allow its massive use particularly in underdeveloped countries [4]. In general the climate does not generate influence on DD if there is a constant exchange of diapers, although it is known that in humid and hot regions there may be a greater number of cases. 


\begin{tabular}{|c|c|c|}
\hline Predisposing factors & $n / \%$ & Etiology \\
\hline Urinary incontinence & $12(54.5 \%)$ & \multirow{4}{*}{$\begin{array}{l}\text { Candida albicans } 14(63.6 \%) \\
\text { Candida glabrata } 04(18.2 \%) \\
\text { Candida parapsilosis } 03(13.6 \%) \\
\text { C. albicans + C. tropicalis } 01(4.5 \%)\end{array}$} \\
\hline Bedridden patient (ICU) & $5(22.7 \%)$ & \\
\hline $\begin{array}{l}\text { Mental disorder } \\
\text { (Alzheimer) }\end{array}$ & $4(18.2 \%)$ & \\
\hline $\begin{array}{l}\text { Topical steroids } \\
\text { (betamethasone) }\end{array}$ & $1(4.5 \%)$ & \\
\hline
\end{tabular}

Table 1: Predisposing factors of 22 cases of diaper dermatitis in the elderly.

\section{Clinical manifestation}

The clinical aspects are similar to those of DD of the infant, affecting the buttocks, perineum, groin and sometimes part of the genitals, constituted by erythema, and edema, when associated with Candida infection, erythematous plaques with papules and pustules are presented in the form of satellite lesions, there may be severe cases with erosion and ulceration $[2,4,13,14]$. In extreme cases granulomatous lesions of the diaper area can be formed with nodular or verrucous lesions $[15,16]$. In general the symptoms of DDE are burning and pruritus, but it is difficult to evaluate the symptoms, particularly in patients with mental damage $[4,10,17,18]$. The most important differential diagnoses are eczema, inverse psoriasis and contact dermatitis $[4,10]$ the latter in particular to substances such as rubber components of retarder vulcanization or adhesives (glues), especially three compounds: mercaptobenzothiazole, p-tertiary-butylphenolformaldehyde resin) and cyclohexylthiophthalimide [10,19].

\section{Laboratory diagnosis}

Because the association by Candida spp. is of great importance for the treatment, it is necessary to have a laboratory diagnosis that is done by direct examination $(10 \% \mathrm{KOH})$ or stains with the presence of pseudohyphae and blastoconidia, and only in C. glabrata infection blastoconidium clusters are seen; the cultures are necessary to know the species, being the CHROMcandida of greater utility. Their identification is confirmed by biochemical, molecular and/or proteomic tests $[1,4]$.

\section{Therapeutic options}

The first therapeutic advice is a constant diaper change that reduces the presence of urine and feces, likewise barrier creams, or emollients such as petrolatums, lanolin and creams with zinc oxide can also be used and control of urinary incontinence is also important $[13,14,20,21]$. Low-potency steroids (hydrocortisone) are only recommended for short time and as long as the DDE is not associated with bacterial or mycotic infections [1,4]. In the initial and small cases of DDE associated with Candida can be treated with topical antimycotics such as nystatin, ciclopirox or imidazole derivatives such as clotrimazole, miconazole, ketoconazole, bifonazole and sertaconazole; they are generally applied twice a day for 7-10 days $[4,22,23]$.

Systemic therapy is recommended only for severe cases and associated with oral, and gastrointestinal infection. The most commonly used drug is fluconazole at doses of 100-150 mg/day for periods of 1 week to 1 month depending on the outcome. (Figure 1).
Nystatin in suspension is also recommended at a dosage of $1 \mathrm{ml} \mathrm{3-4}$ times a day $(100,000 \mathrm{IU})[4,13,14]$.

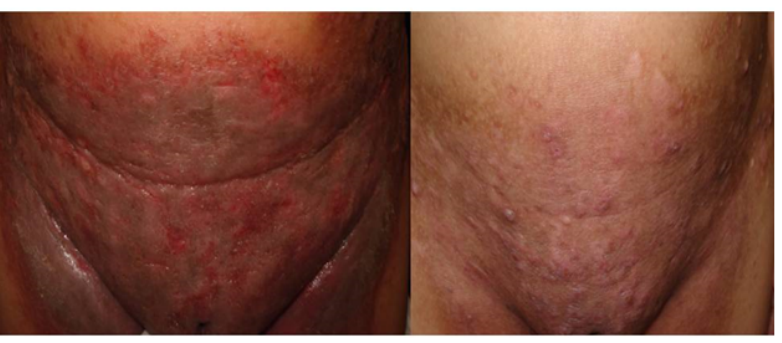

Figure 1: Severe DDE associated to Candida albicans + Candida tropicalis (basal) and after treatment with fluconazole $(150 \mathrm{mg} /$ day per 15 days + sertaconazole $2 \%$ cream twice a day).

In cases of bacterial association, topical treatments applied two or three times daily with bacitracin, fusidic acid and muporocin are recommended, the latter also having moderate action against Candida spp. $[4,10,14]$.

\section{Conclusion}

DDE is a very frequently observed entity, presented mainly in bedridden patients or in those with urinary incontinence who use disposable diapers and its association with Candida is high (60-80\%). DDE in the initial stages can be treated with inert creams and emollients and when there is an infection by Candida, the use of topical antifungals is considered first line treatment and in moderate cases and systemic antifungal in severe cases.

\section{References}

1. Klunk C, Domingues E, Wiss K (2014) An update on diaper dermatitis. Clin Dermatol 32: 477-487.

2. Wolf R, Wolf D, Tüzün B, Tüzün Y (2000) Diaper dermatitis. Clin Dermatol 18: 657-660.

3. Beguin AM, Malaquin-Pavan E, Guihaire C, Hallet-Lezy AM, Souchon S, et al. (2010) Improving diaper design to address incontinence associated dermatitis. BMC Geriatr 10: 86.

4. Bonifaz A, Rojas R, Tirado-Sánchez A, Chávez-López D, Mena C, et al. (2016) Superficial mycoses associated with diaper dermatitis. Mycopathologia 181: 671-679. 
5. Holroyd S, Graham K (2014) Prevention and management of incontinence-associated dermatitis using a barrier cream. $\mathrm{Br} \mathrm{J}$ Community Nurs Sppl Wound Care: S32-S388.

6. Fujimura T, Makino M, Takagi M, Maki K, Murakami E, et al. (2016) The influence of incontinence on the characteristic properties of the skin in bedridden elderly subjects. Int J Dermatol 55: e234-e240.

7. Campbell RL, Bartlett AV, Sarbaugh FC, Pickering LK (1988) Effects of diaper types on diaper dermatitis associated with diarrhea and antibiotic use in children in day-care centers. Pediatr Dermatol 5: 83-87.

8. Allen AM, King RD (1978) Occlusion, carbon dioxide, and fungal skin infections. Lancet 1: 360-362.

9. Akin F, Spraker M, Aly R, Leyden J, Raynor W, et al. (2001) Effects of breathable disposable diapers: reduced prevalence of Candida and common diaper dermatitis. Pediatr Dermatol 18: 282-290.

10. Foureur N, Vanzo B, Meaume S, Senet P (2006) Prospective aetiological study of diaper dermatitis in the elderly. Br J Dermatol 155: 941-946.

11. Dan M, Segal R, Marder V, Leibovitz A (2006) Candida colonization of the vagina in elderly residents of a long-term-care hospital. Eur J Clin Microbiol Infect Dis 25: 394-396.

12. De Bernardis F, Mühlschlegel FA, Cassone A, Fonzi WA (1998) The pH of the host niche controls gene expression in and virulence of Candida albicans. Infect Immun 66: 3317-3325.

13. Boiko S (1999) Treatment of diaper dermatitis. Dermatol Clin 17: 235-240.

14. Henry F, Thirion L, Piérard-Franchimont C, Letawe C, Piérard GE (2006) How I treat diaper dermatitis. Rev Med Liege 61: 212-216.
15. Fujita M, Ohno S, Danno K, Miyachi Y (1991) Two cases of diaper area granuloma of the adult. J Dermatol 18: 671-675.

16. Fernández IS, Moreno C, Vano-Galvan S, Olasolo PJ (2010) Pseudoverrucous irritant peristomal dermatitis with an histological pattern of nutritional deficiency dermatitis. Dermatol Online J 16: 16-19.

17. Farage MA, Miller KW, Berardesca E, Maibach HI (2007) Incontinence in the aged: contact dermatitis and other cutaneous consequences. Contact Dermatitis 57: 211-217.

18. Nazarko L (2007) Managing a common dermatological problem: incontinence dermatitis. Br J Community Nurs 12: 358-359.

19. Roul S, Ducombs G, Leaute-Labreze C, Taieb A (1998) Lucky Luke contact dermatitis due to rubber components of diapers. Contact Dermatitis 38: 363-364.

20. Haugen V (1997) Perineal skin care for patients with frequent diarrhea or fecal incontinence. Gastroenterol Nurs 20: 87-90.

21. Zimmaro Bliss D, Zehrer C, Savik K, Thayer D, Smith G (2006) Incontinence-associated skin damage in nursing home residents: a secondary analysis of a prospective, multicenter study. Ostomy Wound Manage 52: 46-55.

22. Bonifaz A, Tirado-Sánchez A, Graniel MJ, Mena C, Valencia A, et al. (2013) The efficacy and safety of sertaconazole cream (2\%) in diaper dermatitis candidiasis. Mycopathologia 175: 249-254.

23. Mohamadi J, Motaghi M, Panahi J, Havasian MR, Delpisheh A, et al. (2014) Anti-fungal resistance in candida isolated from oral and diaper rash candidiasis in neonates. Bioinformation 27: 667-670. 